\title{
Automated Traffic Enforcement: Responding to the
}

\section{Critics}

\author{
Charles M. Farmer \\ Research and Statistical Services, Insurance Institute for Highway Safety, Ruckersville, VA 22968, USA
}

\begin{abstract}
In many countries, traffic volumes and the number of drivers are rising faster than the availability of police officers whose routine duties include traffic law enforcement. Automated traffic enforcement, which produces photographic evidence of vehicles detected speeding or running red lights, can be used to supplement traditional enforcement. In the United States and Canada, a number of individuals and organizations have been very vocal in their opposition to automated traffic enforcement. They argue that automated enforcement programs are unnecessary for improving road safety, that they unfairly target relatively good drivers, and that they are motivated by revenue generation rather than safety. These arguments, however, often ignore the numerous peer-reviewed studies that have found real-world benefits in communities that use automated enforcement - cameras deter would-be violators, reduce crashes, and save lives. Solid, published research by a number of experts demonstrates that red light cameras save lives, and speed cameras substantially reduce speeding and speed-related crashes. Surveys of drivers and other road users indicate widespread support for automated enforcement. With regard to fairness, the objective of photo enforcement is to deter violations, not to surreptitiously catch violators. The more public the enforcement is, the better. If anything, automated enforcement programs improve fairness by reducing the potential for prejudicial enforcement. Finally, photo enforcement is intended to improve traffic safety by modifying the driver behaviors that lead to crashes, and it is reasonable to expect that people who break the law should pay for enforcing it. Ticket revenue should decline overtime as the cameras succeed in deterring would-be speeders and red light runners. This paper provides research-based responses to the critics' arguments as well as best practice guidelines for effective automated enforcement programs.
\end{abstract}

Key words: Speeding, red-light running, photo enforcement, best practices.

\section{Introduction}

In many countries, traffic volumes and the number of drivers are rising faster than the availability of police officers whose routine duties include traffic law enforcement. Automated traffic enforcement, which produces photographic evidence of vehicles detected speeding or running red lights, can be used to supplement traditional enforcement.

Speeding is a major factor in motor vehicle crashes, especially those resulting in serious injuries [1]. In the United States, speeding - as defined on police crash reports as driving too fast for conditions, exceeding posted speed limits, or racing — was a contributor in $28 \%$ of crash deaths in 2014, resulting in 9,262 deaths [2].

Red light runners cause hundreds of deaths and tens

Corresponding author: Charles M. Farmer, vice president, research fields: traffic safety, driver behavior, and evaluation studies. E-mail: cfarmer@iihs.org. of thousands of injuries in the United States each year. In 2014, 709 people were killed and an estimated 126,000 were injured in crashes that involved red light running. More than half of those killed were pedestrians, bicyclists, and people in other vehicles who were hit by the red light runners [3].

Guidelines for the start-up and operation of automated enforcement were published in 2012 by the NCHRP (National Cooperative Highway Research Program), an effort funded by U.S. state departments of transportation and administered by the Transportation Research Board [4]. These guidelines were based on a comprehensive review of automated speed and red light enforcement programs in the United States and Canada. Their purpose was to encourage and aid other communities when considering automated enforcement.

Despite the demonstrated success of programs across 
the United States and Canada, a number of individuals and organizations have been very vocal in their opposition to automated traffic enforcement. They argue that automated enforcement programs are unnecessary for improving road safety. In brief, the main points raised by critics of automated enforcement are:

(1) Automated enforcement does not change driver behavior;

(2) Automated enforcement does not prevent crashes;

(3) There are better ways to reduce violation rates;

(4) Strict enforcement targets relatively good drivers rather than the few dangerous drivers;

(5) The equipment used may not be reliable;

(6) Alleged violators are not promptly notified;

(7) Drivers are unaware of the increased enforcement;

(8) Automated enforcement is motivated by revenue generation rather than safety;

(9) Automated enforcement locations are chosen so as to maximize violation rates;

(10) Automated enforcement is unfair.

This paper provides research-based responses to the above arguments as well as best practice guidelines for effective automated enforcement programs.

\section{Responding to the Critics}

\subsection{Automated Enforcement Does Not Change Driver}

\section{Behavior}

Automated speed enforcement can substantially reduce speeding on a wide range of roads. Studies of cameras on residential roads in Maryland, on a high-speed road way in Arizona, and on city streets in the District of Columbia found that the proportion of drivers exceeding speed limits by more than $10 \mathrm{mph}$ declined by $70 \%, 88 \%$, and $82 \%$, respectively, $6 \sim 8$ months after cameras were introduced [5-7]. A 2015 study in Montgomery County, Maryland, found that about $7 \frac{1}{2}$ years after the speed camera program began, the cameras were associated with a $10 \%$ reduction in mean speeds and a $59 \%$ reduction in the likelihood that a vehicle was traveling more than $10 \mathrm{mph}$ above the speed limit on camera-eligible roads, almost all of which had cameras [8].

A 2010 review published by the Cochrane Collaboration, an international public health organization, examined 35 studies from various countries. The authors concluded that speed cameras - including fixed, mobile, overt, and covert devices - cut average speeds by $1 \% \sim 15 \%$ and the percentage of vehicles traveling above the speed limits or designated speed thresholds by $14 \% \sim 65 \%$ compared with sites without cameras [9].

A series of studies in different communities found that red light violations are reduced significantly with cameras. Studies in Oxnard, California, and in Fairfax, Virginia, reported reductions in red light violation rates of about $40 \%$ after the introduction of red light cameras $[10,11]$. In addition to the decrease in red light running at camera-equipped sites, the effect carried over to nearby signalized intersections not equipped with red light cameras. A review of international red light camera studies concluded that cameras lower red light violations by $40 \% \sim 50 \%$ [12].

A more recent study in Arlington, Virginia, also found significant reductions in red light violations at camera intersections1 year after ticketing began [13]. These reductions were greater the more time had passed since the light turned red, when violations are more likely to result in crashes. Violations occurring at least a half second after the light turned red were 39\% less likely than would have been expected without cameras. Violations occurring at least 1 second after were $48 \%$ less likely, and the odds of a violation occurring at least 1.5 seconds into the red phase fell $86 \%$.

\subsection{Automated Enforcement Does Not Prevent Crashes}

On the contrary, there is overwhelming evidence that automated enforcement improves highway safety. Research in Oxnard, California, found significant city 
wide crash reductions followed the introduction of red light cameras, and injury crashes at intersections with traffic signals were reduced by 29\% [14]. Front-into-side collisions - the crash type most closely associated with red light running-at these intersections declined by $32 \%$ overall, and front-into-side crashes involving injuries fell $68 \%$.

A review of international red light camera studies concluded that cameras reduce injury crashes by $25 \% \sim 30 \%$ [12]. In 2005, the Cochrane Collaboration reviewed 10 controlled before-after studies of red light camera effectiveness [15]. Based on the most rigorous studies, there was an estimated $13 \% \sim 29 \%$ reduction in all types of injury crashes and a $24 \%$ reduction in right-angle injury crashes. The review did not find a statistically significant change in rear-end injury crashes.

A study sponsored by the U.S. Federal Highway Administration evaluated red light camera programs in seven cities [16]. The study found that, overall, right-angle crashes decreased by $25 \%$ while rear-end collisions increased by $15 \%$. Results showed a positive aggregate economic benefit of more than $\$ 18.5$ million in the seven communities. The authors concluded that the economic costs from the increase in rear-end crashes were more than offset by the economic benefits from the decrease in right-angle crashes targeted by red light cameras.

A 2016 study comparing large cities with red light cameras to those without found that the devices reduced the fatal red light running crash rate by $21 \%$ and the rate of all types of fatal crashes at signalized intersections by $14 \%$ [17]. The same study also looked at what happens when communities end the use of red light cameras. In 14 cities that shut down their programs during 2010-2014, the fatal red light running crash rate was $30 \%$ higher than would have been expected if they had left the cameras on. The rate of fatal crashes at signalized intersections was $16 \%$ higher.

In 2010, the Cochrane Collaboration reviewed 28 studies that reported the effect of speed cameras on crashes and found reductions of $8 \% \sim 49 \%$ for all crashes, $8 \% \sim 50 \%$ for injury crashes, and $11 \% \sim 44 \%$ for crashes involving fatalities and serious injuries, in the vicinity of camera sites [9]. Over wider areas, the review found reductions of $9 \% \sim 35 \%$ for all crashes and $17 \% \sim 58 \%$ for crashes involving fatalities and serious injuries. Reviewed studies with longer durations showed that these trends were either maintained or improved with time.

A 2016 study in Montgomery County, Maryland, found that speed camera enforcement was associated with a $12 \%$ reduction in the likelihood that a crash on a camera-eligible road was speeding-related and a $19 \%$ reduction in the likelihood that a crash involved an incapacitating or fatal injury [8]. A corridor approach, in which cameras were periodically moved along the length of a roadway segment, provided an additional $30 \%$ reduction in the likelihood that a crash involved an incapacitating or fatal injury over and above the effect of the cameras.

\subsection{There Are Better Ways to Reduce Violation Rates}

Roadside electronic signs that display vehicle speeds to warn drivers they are speeding can reduce speeds in the immediate area of the signs [18]. However, without an associated police presence, motorists begin to ignore the signs. Speeding also can be reduced through traffic-calming measures such as speed humps and lane narrowing, but these measures require costly and time-consuming infrastructure changes [19].

For red light cameras, it is important to conduct a thorough engineering study of each intersection to make sure the red light running problem is not the result of poor signal timing or visibility. Signals must have an adequate yellow time and, if allowed under state law, an all-red phase. Providing adequate yellow signal time is important and can reduce crashes. Studies have shown that increasing yellow timing to values associated with guidelines published by the Institute of Transportation Engineers [20] can 
significantly decrease the frequency of red light violations and reduce the risk of total crashes, injury crashes, and right-angle crashes [21-23]. However, adjusting yellow signal time alone does not eliminate the need for enforcement of red light violations. A study conducted in Philadelphia, Pennsylvania, evaluated effects on red light running of first lengthening yellow signal timing by about a second and then introducing red light cameras [24]. While the longer yellow signal reduced red light violations by $36 \%$, adding camera enforcement further cut red light running by another $96 \%$.

\subsection{Strict Enforcement Targets Relatively Good Drivers Rather than the Few Dangerous Drivers}

Speeding and red light running increase the risk to all road users-motorists, motorcyclists, bicyclists, and pedestrians. Enforcing traffic laws makes roads safer. Although automated traffic enforcement is more persistent than traditional police enforcement, it is no more strict in its interpretation of violations.

Speed cameras usually are programmed so they will not be activated unless a vehicle is traveling significantly faster than the posted limit, typically 10 or $11 \mathrm{mph}$ faster. An observational study conducted on roads with speed limits ranging from 40 to $55 \mathrm{mph}$ compared drivers traveling at least $15 \mathrm{mph}$ above posted speed limits with drivers of adjacent vehicles traveling no more than $5 \mathrm{mph}$ above the speed limit [25]. Speeders were younger than drivers in the comparison group and had more violations and crashes on their driver records.

Many red light camera programs provide motorists with grace periods of up to a half second after the light switches to red. A 1996 study of red light runners at one Arlington, Virginia, intersection found that, as a group, they were younger and less likely to use safety belts and had poorer driving records than drivers who stopped for red lights [26]. Red light runners were more than three times as likely to have multiple speeding convictions on their driver records.

\subsection{The Equipment Used May Not Be Reliable}

Equipment used for automated enforcement should be checked and calibrated periodically to minimize errors [4]. In addition, it is standard practice for trained police officers or authorized civilian employees to review every picture to verify vehicle information and ensure that the vehicle is in violation. A ticket is issued only if there is clear evidence that the vehicle was speeding or ran a red light [16].

\subsection{Alleged Violators Are Not Promptly Notified}

In some circumstances, even traditional enforcement methods do not provide immediate notice. An officer who observes a violation can cite the violator at a later time. In crash situations, citations often are issued after the investigation is completed, days or weeks after the crash. According to the NCHRP guidelines, jurisdictions should require that a violation notice be served within 14 days of the alleged violation [4]. Some jurisdictions impose even tighter time limits. For example, Portland, Oregon, requires that the notice be mailed within six business days of the alleged violation.

\subsection{Drivers Are Unaware of the Increased Enforcement}

The objective of photo enforcement is to deter violations, not to surreptitiously catch violators. The more public the enforcement is, the better. Photo-enforcement cameras are in plain view, not hidden. Typically, there are signs and publicity campaigns warning drivers that photo enforcement is in use. The NCHRP guidelines recommend conducting a public information campaign to explain the dangers of speeding and red light running and how the camera program will work before activating the cameras [4]. It is also common for jurisdictions to introduce new automated enforcement programs with a 30-day period during which only warning notices are issued.

\subsection{Automated Enforcement Is Motivated by Revenue Generation Rather than Safety}

Photo enforcement is intended to improve traffic 
safety by modifying the driver behaviors that lead to crashes, and it is reasonable to expect that people who break the law should pay for enforcing it. The NCHRP guidelines recommend that money from citations be used to pay for the cameras, and any excess should go to other highway safety programs [4]. Ideally, ticket revenue should decline overtime as the cameras succeed in deterring would-be speeders and red light runners.

A few well-publicized cases involving elected officials who accepted cash and perks from a camera vendor in exchange for help in securing automated enforcement contracts have stirred controversy and highlight the potential for abuse [27, 28]. However, these corruption cases should not overshadow the demonstrated safety benefits of automated enforcement. It makes no sense to ban a life-saving program because of several corrupt individuals. Rather, the program should receive sufficient oversight that such corruption cannot occur.

\subsection{Automated Enforcement Locations Are Chosen So as to Maximize Violation Rates}

Photo enforcement sites are generally well-publicized, which is key to their strong deterrent effect. Speed cameras should not be confused with so-called "speed traps" and "secret" enforcement. Unlike speed traps, photo enforcement is fair. Only violators who meet objective criteria specifically designed to omit minor, unintended infractions are ticketed. Speed cameras are usually programmed so they will not be activated unless a vehicle is traveling significantly faster than the posted limit, typically 10 or $11 \mathrm{mph}$ faster, although in certain places such as school zones, the tolerance may be lower. Photo enforcement programs are also designed to distinguish legal maneuvers, such as turning right on red or being caught in the intersection when the light changes, from red light violations. Photo enforcement also reduces the potential for impermissible profiling or discriminatory enforcement.
Speed limits are lower in school zones, construction zones, and residential neighborhoods for safety, not to inconvenience drivers. School zones and residential neighborhoods have higher amounts of pedestrian traffic, and both traffic engineers and the general public recognize the need for lower speed limits in these areas [29]. A 2015 national survey of drivers ages 16 and older indicated that $35 \%$ supported the use of speed cameras on freeways or interstates, $45 \%$ supported their use on residential streets, and 55\% supported their use in school zones [30]. Support is even more striking among those in jurisdictions with cameras. A 2012 survey of 801 District of Columbia residents found strong support for speed cameras [31]. The District has used speed cameras since 2001. In the survey, $88 \%$ of residents said that speeding was a serious threat to their personal safety. A 2014 survey of 900 licensed drivers ages 18 and older residing in Montgomery County, Maryland, found that $62 \%$ of drivers favored automated speed enforcement on residential streets about $7 \frac{1}{2}$ years after camera ticketing began [8].

\subsection{Automated Enforcement Is Unfair}

If anything, automated traffic enforcement programs improve fairness by reducing the potential for prejudicial enforcement. And, if it is unjustifiable to enforce laws, especially laws with proven safety benefits, then what is the purpose of the laws?

\section{Best Practices}

Automated enforcement programs have been successfully run in a number of communities for more than 20 years. These communities provide evidence of what works and what does not work. Some of these best practices are listed below.

- Automated enforcement should not be the sole approach to solving a safety problem. As such, automated enforcement should be part of a comprehensive program that includes traditional engineering, education, and enforcement measures; 
- Gain support from the public and other government departments. Publicize the extent of the safety problem and the need for innovative solutions. Then design the program as a group project, involving stakeholders such as enforcement agencies, transportation departments, and representatives of the community;

- Connect the program to a long-term safety goal. Stress that the goal of the program is to make the roads safer. This message is strengthened by including the program as part of a Vision Zero or similar plan;

- Introduce a media campaign focused on changing driver attitudes and behavior. If the public believes that speeding and red light running are dangerous, then such activities will not be acceptable;

- Include a probationary period during which only warnings are issued to violators. Also, post warning signs in the areas where cameras are being used. A gradual introduction of the program and reminders of its existence help to inform the public and gain acceptance;

- Focus on the most blatant violations. Select sites for automated enforcement that have documented safety issues. Also, as with traditional enforcement, target those violations with greater safety consequences, e.g., speeding by more than $10 \mathrm{mph}$ and entering an intersection more than a half second into the red phase;

- Be transparent. Information regarding the setup and operation of the program should be public. Any changes, including new camera locations, should be advertised;

- Allow for due process. Publicize the procedures available for contesting an alleged violation. Although "a picture is worth a thousand words," it does not necessarily tell the whole story;

- Devote all surplus revenue to safety initiatives. Again, make it clear that the automated enforcement program is about safety. Do not design budgets that include projected revenue from the cameras. If successful, the cameras will not produce any revenue;
- Continually gather data to show evidence of a program effect. Statistics on speeding and red light running violations as well as crashes should be summarized periodically. These summaries, along with clear explanations, should be provided to all stakeholders.

\section{Conclusions}

Automated traffic enforcement works, but it is important to show that it works. In order to retain public support for the program, keep the community involved and invested, be clear about how the program is run, be clear that the goal of the program is to make the roads safer, and provide clear evidence that the program is achieving that goal.

\section{References}

[1] Elvik, R. 2005. "Speed and Road Safety: Synthesis of Evidence from Evaluation Studies." Transportation Research Record 1908: 59-69. Washington, DC: Transportation Research Board.

[2] Insurance Institute for Highway Safety. 2016. "Fatality Facts: Yearly Snapshot, 2014.” Arlington, VA. Accessed September 30, 2016. http://www.iihs.org/iihs/topics/t/ general-statistics/fatalityfacts/overview-of-fatality-facts\# Speeding.

[3] Insurance Institute for Highway Safety. 2016. "Q\&As: Red Light Running.” Arlington, VA. Accessed September 30, 2016. http://www.iihs.org/iihs/topics/t/red-lightrunning/qanda\#tred-light-running.

[4] Eccles, K. A., Fiedler, R., Persaud, B., Lyon, C., and Hansen, G. 2012. Automated Enforcement for Speeding and Red Light Running. National Cooperative Highway Research Program Report No. 729. Washington, DC: Transportation Research Board.

[5] Retting, R. A., Farmer, C. F., and McCartt, A. T. 2008. "Evaluation of Automated Speed Enforcement in Montgomery County, Maryland." Traffic Injury Prevention 9: 440-5.

[6] Retting, R. A., Kyrychenko, S. Y., and McCartt, A. T. 2008. "Evaluation of Automated Speed Enforcement on Loop 101 Freeway in Scottsdale, Arizona." Accident Analysis and Prevention 40:1506-12.

[7] Retting, R. A., and Farmer, C. M. 2003. "Evaluation of Speed Camera Enforcement in the District of Columbia." Transportation Research Record 1830: 34-7.

[8] Hu, W., and McCartt, A. T. 2016. "Effects of Automated Speed Enforcement in Montgomery County, Maryland, 
on Vehicle Speeds, Public Opinion, and Crashes." Traffic Injury Prevention 17 (S1):5 3-8.

[9] Wilson, C., Willis, C., Hendrikz, J. K., LeBrocque, R., and Bellamy, N. 2010. "Speed Cameras for the Prevention of Road Traffic Injuries and Deaths." The Cochrane Library 2010, Issue10. Oxfordshire, England: The Cochrane Collaboration.

[10] Retting, R. A., Williams, A. F., Farmer, C. M., and Feldman, A. F. 1999. "Evaluation of Red Light Camera Enforcement in Fairfax, Va., USA." ITE Journal 69: 30-4.

[11] Retting, R.A., Williams, A. F., Farmer, C. M., and Feldman, A. F. 1999. "Evaluation of Red Light Camera enforcement in Oxnard, California." Accident Analysis and Prevention 31: 169-74.

[12] Retting, R. A., Ferguson, S. A., and Hakkert, A. S. 2003. "Effects of Red Light Cameras on Violations and Crashes: A Review of the International Literature." Traffic Injury Prevention 4: 17-23.

[13] McCartt, A. T., and Hu, W. 2014. "Effects of Red Light Camera Enforcement on Red light Violations in Arlington County, Virginia." Journal of Safety Research 48: 57-62.

[14] Retting, R. A., and Kyrychenko, S. Y. 2002. "Reductions in Injury Crashes Associated with Red Light Camera Enforcement in Oxnard, California." American Journal of Public Health 92: 1822-25.

[15] Aeron-Thomas, A. S., and Hess, S. 2005. "Red-Light Cameras for the Prevention of Road Traffic Crashes." The Cochrane Library 2005, Issue2. Oxfordshire, England: The Cochrane Collaboration.

[16] Council, F., Persaud, B., Eccles, K., Lyon, C., and Griffith, M. 2005. Safety Evaluation of Red-Light Cameras. Report no. FHWAHRT-05-048. Washington, DC: Federal Highway Administration.

[17] Hu, W., and Cicchino, J. B. 2016. Effects of Turning on and off Red Light Cameras on Fatal Crashes in Large US Cities. Arlington, VA: Insurance Institute for Highway Safety.

[18] Casey, S. M., and Lund, A. K. 1993. "The Effects of Mobile Roadside Speedometers on Traffic Speeds." Accident Analysis and Prevention 25: 627-34.

[19] Bunn, F., Collier, T., Frost, C., Kerr, K., Roberts, I., and Wentz, R. 2003. "Area-Wide Traffic Calming for Preventing Traffic Related Injuries." The Cochrane Library 2003, Issue1. Oxfordshire, England: The Cochrane Collaboration.
[20] Institute of Transportation Engineers. 1985. Determining Vehicle Change Intervals: A Recommended Practice. Washington, DC: Institute of Transportation Engineers.

[21] Bonneson, J. A., and Zimmerman, K. H. 2004. "Effect of Yellow-Interval Timing on the Frequency of Red-Light Violations at Urban Intersections." Transportation Research Record 1865:20-7.

[22] Retting, R. A., and Greene, M. A. 1997. "Influence of Traffic Signal Timing on Red Light Running and Potential Vehicle Conflicts at Urban Intersections." Transportation Research Record 1595: 1-7.

[23] McGee, H., Moriarty, K., Eccles, K., Liu, M., Gates, T., and Retting, R. A. 2012. Guidelines for Timing Yellow and All-Red Intervals at Signalized Intersections. National Cooperative Highway Research Report No. 731. Washington, DC: Transportation Research Board.

[24] Retting, R. A., Ferguson, S. A., and Farmer, C. M. 2008. "Reducing Red Light Running through Longer Yellow Signal Timing and Red Light Camera Enforcement: Results of a Field Investigation." Accident Analysis and Prevention 40 (1): 327-33.

[25] Williams, A. F., Kyrychenko, S. Y., and Retting, R. A. 2006. "Characteristics of Speeders." Journal of Safety Research 37: 227-32.

[26] Retting, R. A., and Williams, A. F. 1996. "Characteristics of Red Light Violators: Results of a Field Investigation." Journal of Safety Research 27: 9-15.

[27] Peters, M. 2016. "Jury Finds Chicago Official Guilty of Bribery in Red-Light Camera Scandal." The Wall Street Journal, Jan. 26.

[28] Sullivan, L. 2015. "Columbus Cancels Red-Light Camera Contract after Bribe Investigation." The Columbus Dispatch, July 15.

[29] Ullman, G. L., Brewer, M. A., Bryden, J. E., Corkran, M. O., Hubbs, C. W., Chandra, A. K., and Jeannotte, K. L. 2013. Traffic Enforcement Strategies for Work Zones. National Cooperative Highway Research Program Report No. 746. Washington, DC: Transportation Research Board.

[30] AAA Foundation for Traffic Safety. 2016. 2015 Traffic Safety Culture Index. Washington, DC: AAA Foundation for Traffic Safety.

[31] Cicchino, J. B., Wells, J. K., and McCartt, A. T. 2014. "Survey about Pedestrian Safety and Attitudes toward Automated Traffic Enforcement in Washington, D.C." Traffic Injury Prevention 15 (4): 414-23. 